Supporting Information

\title{
Spatial ordering of the structure of polymer-capped
}

\section{gold nanorods under an external DC electric field}

Toshiaki Fukagawa ${ }^{a}$ Hiroaki Tanaka $^{a}$, Kouki Morikawa ${ }^{a}$,

Shunsuke Tanaka ${ }^{a}$, Yoshikiyo Hatakeyama $^{b}$, Kazuyuki Hino $^{a, *}$

${ }^{a}$ Department of Chemistry, Faculty of Education, Aichi University of Education, 1 Hirosawa, Igaya, Kariya, Aichi 448-8542, Japan

${ }^{b}$ Division of Molecular Science, Faculty of Science and Technology, Gunma University, 1-5-1

Tenjin-cho, Kiryu, Gunma 376-8515, Japan

The GNRs were prepared by an improved seed-mediated method. ${ }^{1}$ A binary surfactant mixture consisting of cetyltrimethylammonium bromide (CTAB) and sodium oleate (NaOL) yields a more monodispersed and thicker sample (length $<100 \mathrm{~nm}$, width $<50 \mathrm{~nm}$ ) than singlecomponent $\mathrm{CTAB}, 2,3$ for several reasons. First, the double-component surfactant stabilizes the mixed template micelles for nanoparticles. ${ }^{4,5}$ Second, the presence of silver ions clarifies the 
growth direction of GNRs. ${ }^{6,7}$ Then, the additive hydrochloric acid adjusts the $\mathrm{pH}$, and hence controls the growth speed of the GNRs. ${ }^{8,9}$

The seed solution was prepared by mixing $5 \mathrm{~mL}$ of $\mathrm{HAuCl}_{4}(0.5 \mathrm{mM})$ and $5 \mathrm{~mL}$ of CTAB $(0.2$ M) in a $10 \mathrm{~mL}$ vial. Next, $0.6 \mathrm{~mL}$ of freshly prepared $\mathrm{NaBH}_{4}(0.01 \mathrm{M})$ was added to this solution, followed by vigorous stirring for $2 \mathrm{~min}$. The color of the solution changed from yellow to brownish yellow. The seed solution was aged for $30 \mathrm{~min}$ at $30{ }^{\circ} \mathrm{C}$ before use.

To generate GNRs with AR 4.0, $0.9 \mathrm{~g}$ of CTAB and $0.1234 \mathrm{~g}$ of NaOL were dissolved in 25 $\mathrm{mL}$ water at $55{ }^{\circ} \mathrm{C}$ in a $50-\mathrm{mL}$ vial. After allowing the solution to cool to $30^{\circ} \mathrm{C}$, a quota volume of $\mathrm{AgNO}_{3}(4 \mathrm{mM})$ and $25 \mathrm{~mL}$ of $\mathrm{HAuCl}_{4}(1 \mathrm{mM})$ was added. The solution was stirred for $90 \mathrm{~min}$ and the $\mathrm{pH}$ was adjusted with a quota volume of concentrated $\mathrm{HCl}$. The mixture was stirred for $15 \mathrm{~min}$. Then, $0.125 \mathrm{~mL}$ of ascorbic acid $(6.4 \mathrm{mM})$ was added and the mixture was stirred vigorously for $30 \mathrm{~s}$. This mixture was named the growth solution. Finally, a small amount of seed solution was added to the growth solution and aged at $30{ }^{\circ} \mathrm{C}$ for $12 \mathrm{~h}$.

In a $50-\mathrm{mL}$ vial, $33.25 \mathrm{mg}\left(6.3 \times 10^{-7} \mathrm{~mol}\right)$ of polymer thiol (thiol-terminated polystyrene: $\mathrm{Mn}$ $=5.0 \times 10^{4}, \mathrm{Mw}=5.3 \times 10^{4}, \mathrm{Mw} / \mathrm{Mn}=1.06$, Polymer Source, Inc., Quebec, CANADA) was dissolved in $25 \mathrm{~mL}$ of tetrahydrofuran (THF). The GNRs previously generated were added to this solution, and the mixture was stirred for $1 \mathrm{~h}$. During this time, the mixed solution became colorless and a reddish-brown precipitate was formed. The precipitate was collected by centrifugation, washed with THF/water to remove the excess polymer thiol and surfactants, and dried in vacuo. The resulting polymer-capped GNRs (GNRs@PS) were used in further experiments. ${ }^{10}$ 
We have developed a system for electric field application experiments. ${ }^{11}$ Fig. S1 is a schematic of a sample cell and a holder. The sample cell comprises two sheets of indium tin oxide (ITO) side-coated glass and a spacer. The $300 \mu \mathrm{m}$-thick spacer is sandwiched between two parallel 150 $\mu \mathrm{m}$-thick glass plates, with the ITO sides facing outward. The path length of the cell is $300 \mu \mathrm{m}$. A high DC voltage (up to $4.00 \mathrm{~V} / \mu \mathrm{m}$, provided by a PowerPac HV, Bio-Rad, California, USA) is applied between the electrodes (a distance of $600 \mu \mathrm{m}$ ), providing an electric field strength of up to $4.00 \mathrm{~V} / \mu \mathrm{m}$. The cell holder is made from highly insulating polyether ether ketone.

(a)



(b)

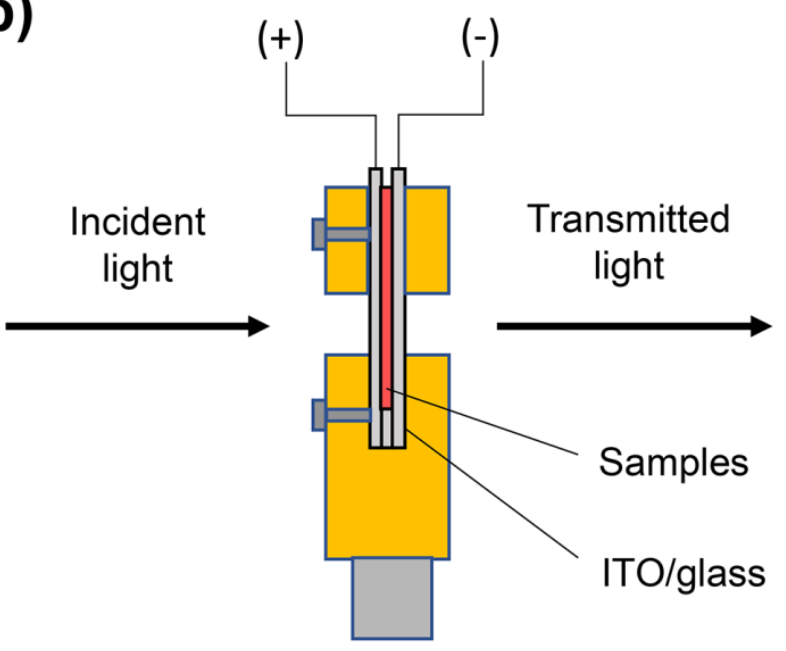

Figure S1. (a) Schematic of a sample cell with the translucent ITO sides facing outward. The ITO electrodes are separated by $600 \mu \mathrm{m}$. The solution layer is $300 \mu \mathrm{m}$ deep, and the maximum electric field strength is $\sim 4.00 \mathrm{~V} / \mu \mathrm{m}$. (b) Schematic of a cell holder. 


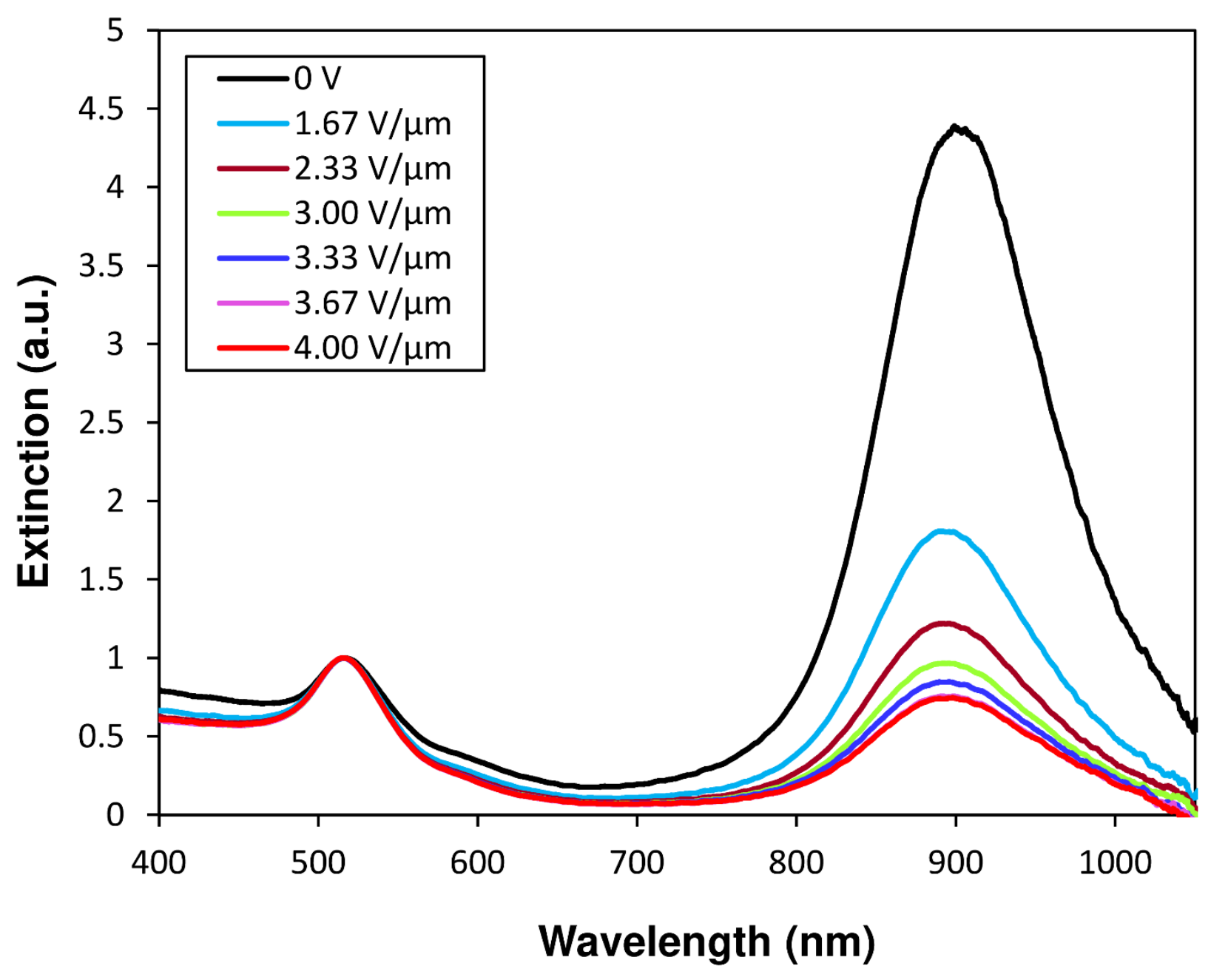

Figure S2. Absorption spectra of GNRs@PS (AR = 4.0) in toluene under an applied electric field. The spectra were normalized to the maximum extinction of the transverse plasmon band. 
(a)

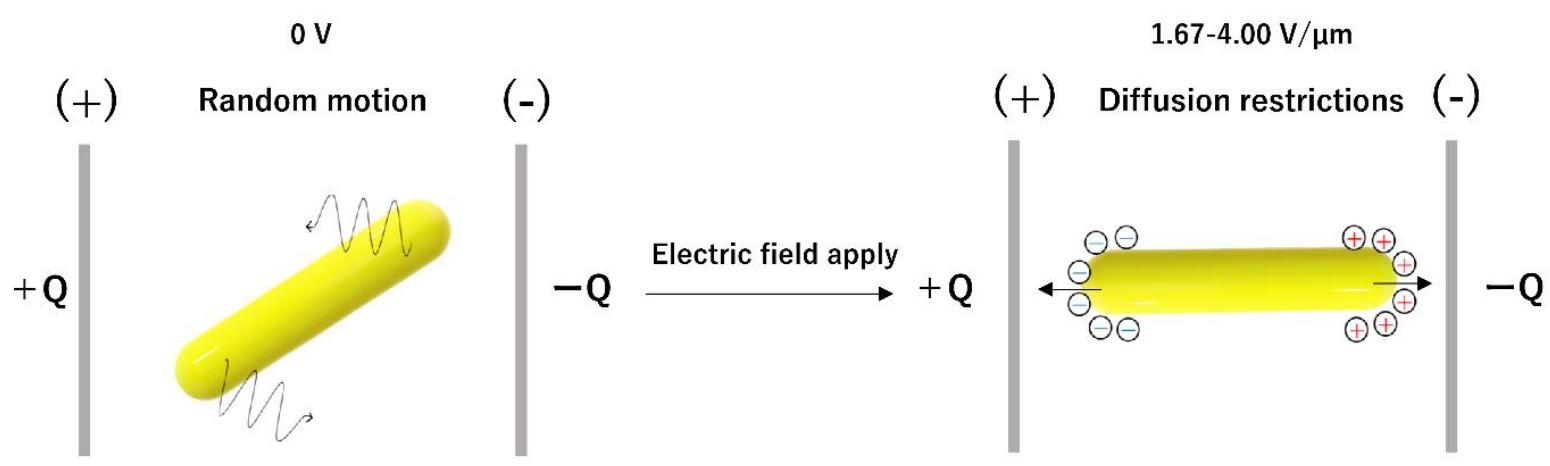

(b)

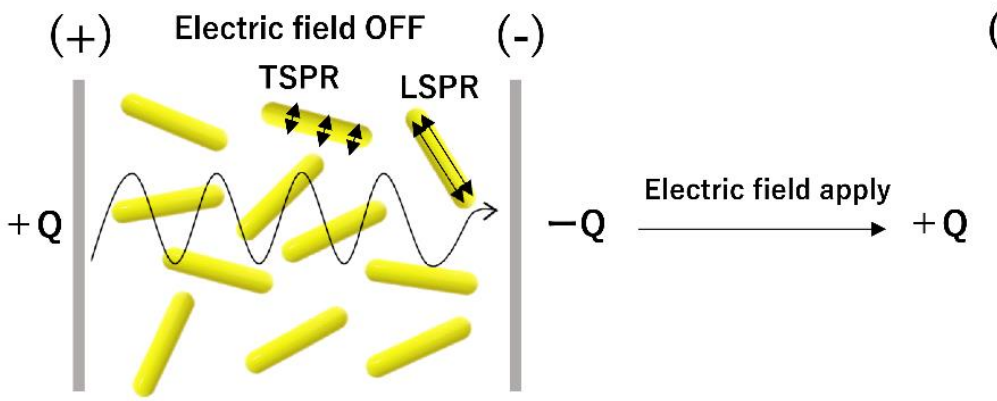

(+) Electric field ON

$(-)$

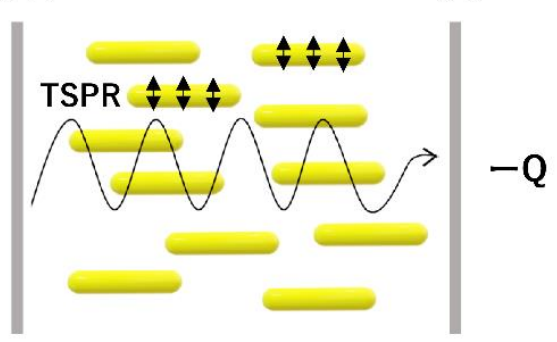

Figure S3. (a) Schematic of the charges induced in GNRs@PS under an electric field. $Q$ denotes the quantity of the induced charges. (b) Alignment changes of GNRs@PS under the application of electric field. Linearly polarized light aligns with the applied electric field. TSPR or LSPR represents the transverse or longitudinal surface plasmon resonance, respectively. 


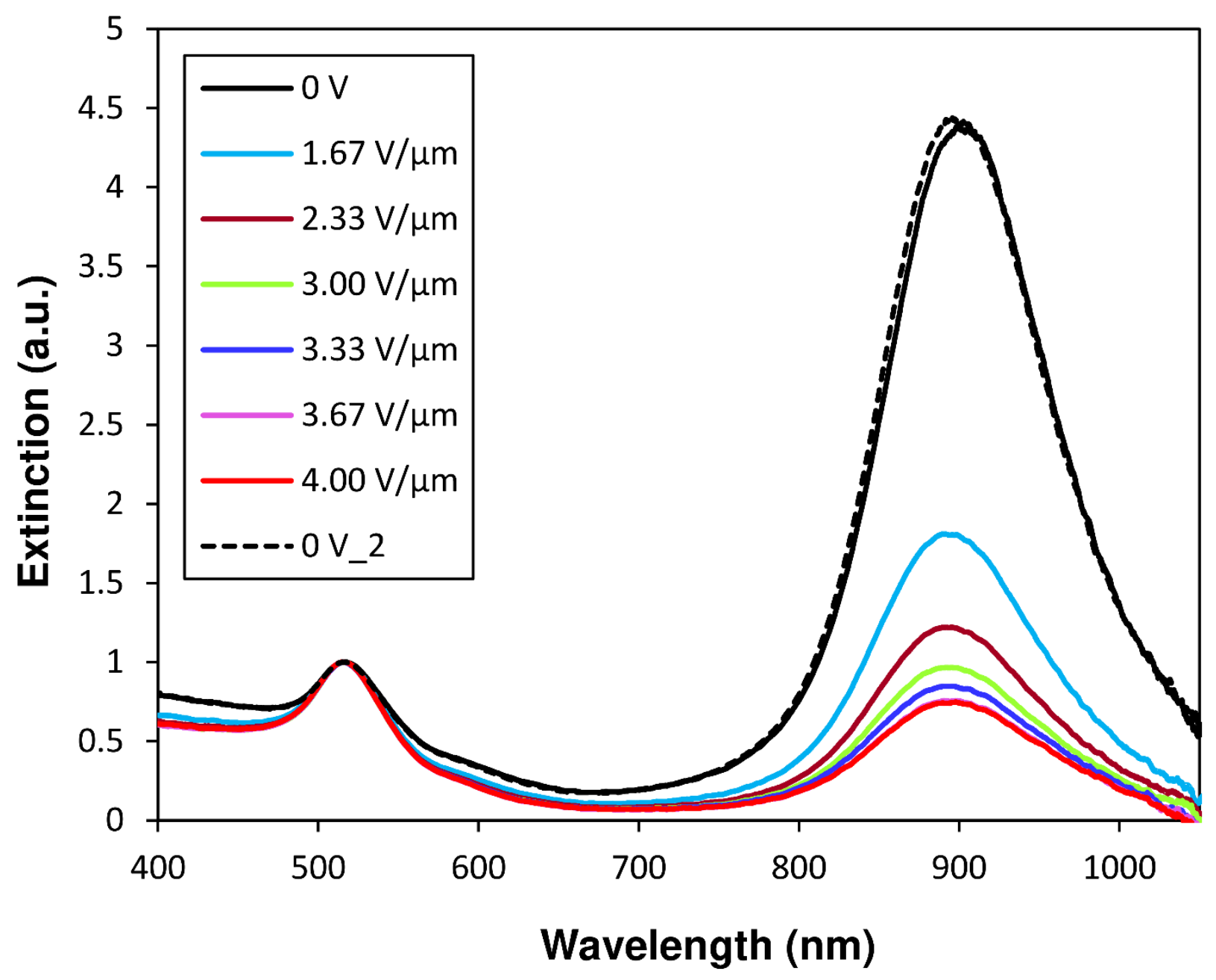

Figure S4. Absorption spectrum of AR4 GNRs@PS in toluene solution under the applied electric field. The dashed line is the spectrum when the electric field was turned off after 4.00 $\mathrm{V} / \mu \mathrm{m}$. The spectrum almost matches that at $0 \mathrm{~V}$, indicating that the arrayed GNRs@PS returned to random motions after the electric field cutoff $\left(0 \mathrm{~V} \_2\right)$. 


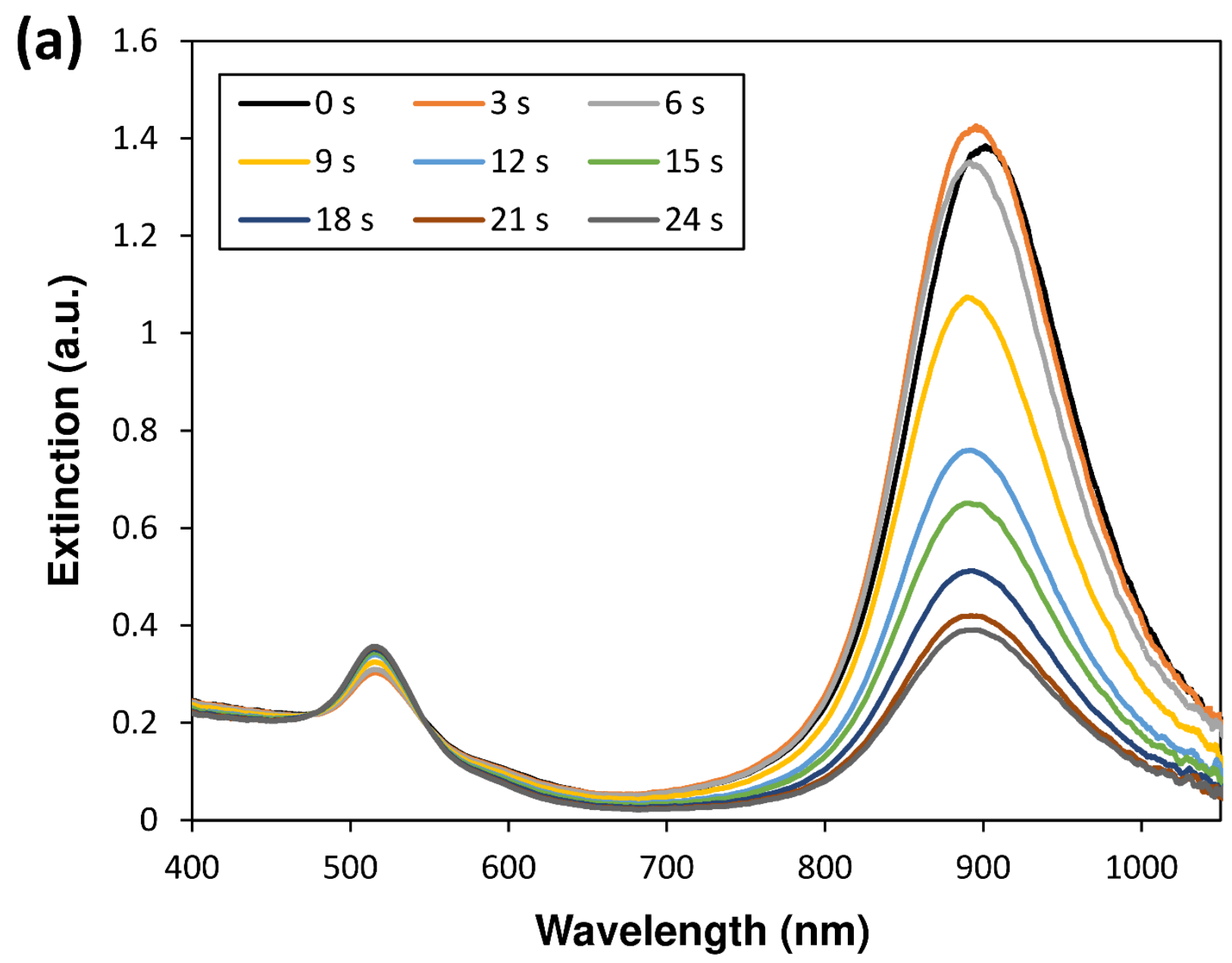




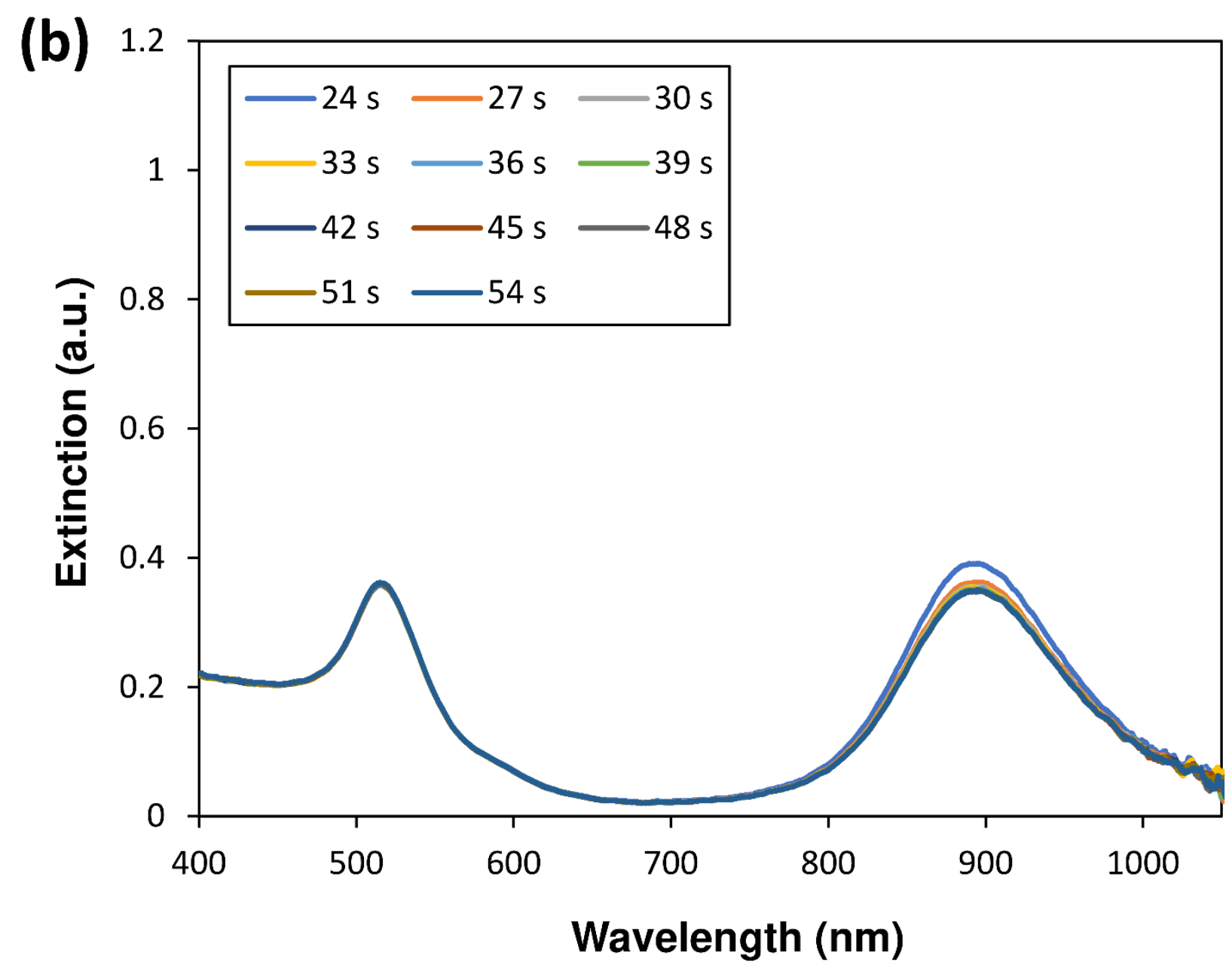




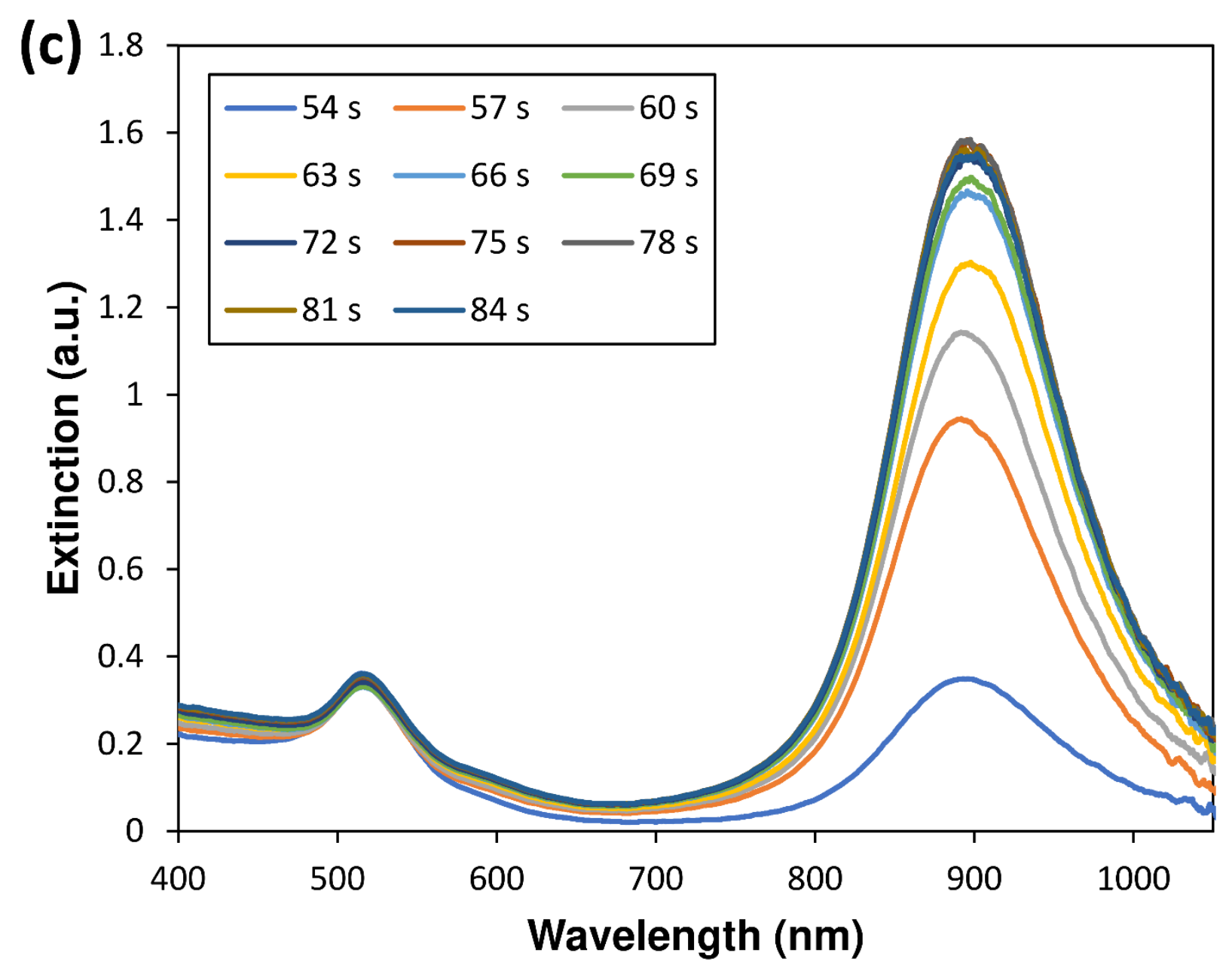

Figure S5. Spectral evolutions of the alignment: (a) for 24 seconds while turning up DC field strength from zero to $3.33 \mathrm{~V} / \mu \mathrm{m}$, (b) for 30 seconds while maintaining the set strength of 3.33 $\mathrm{V} / \mu \mathrm{m}$, and (c) for 30 seconds while turning down from $3.33 \mathrm{~V} / \mu \mathrm{m}$ to zero. 


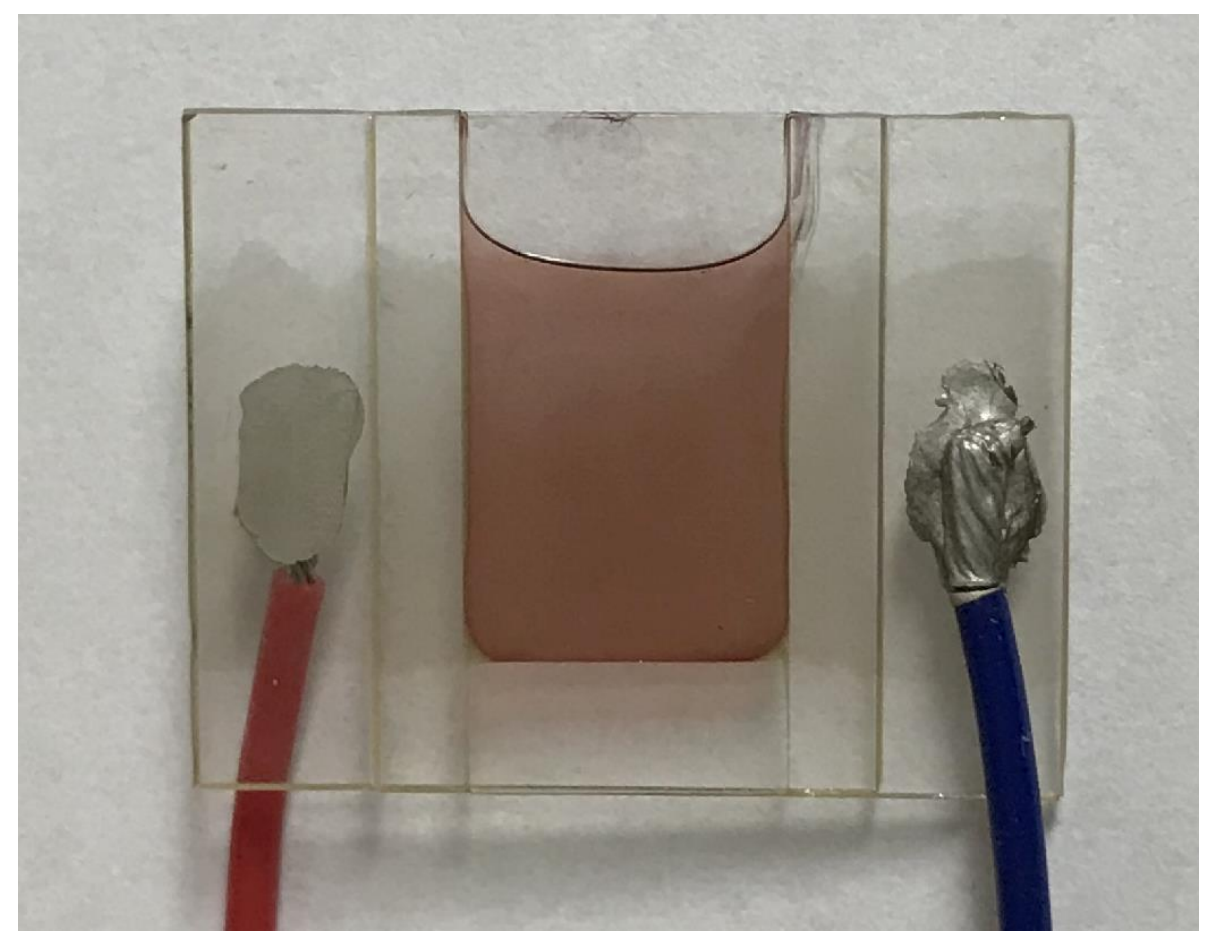

Figure S6. Negligible deposition of GNRs@PS on the cell after applying an electric field. This phenomenon can cause the absorbance to change very slightly. 

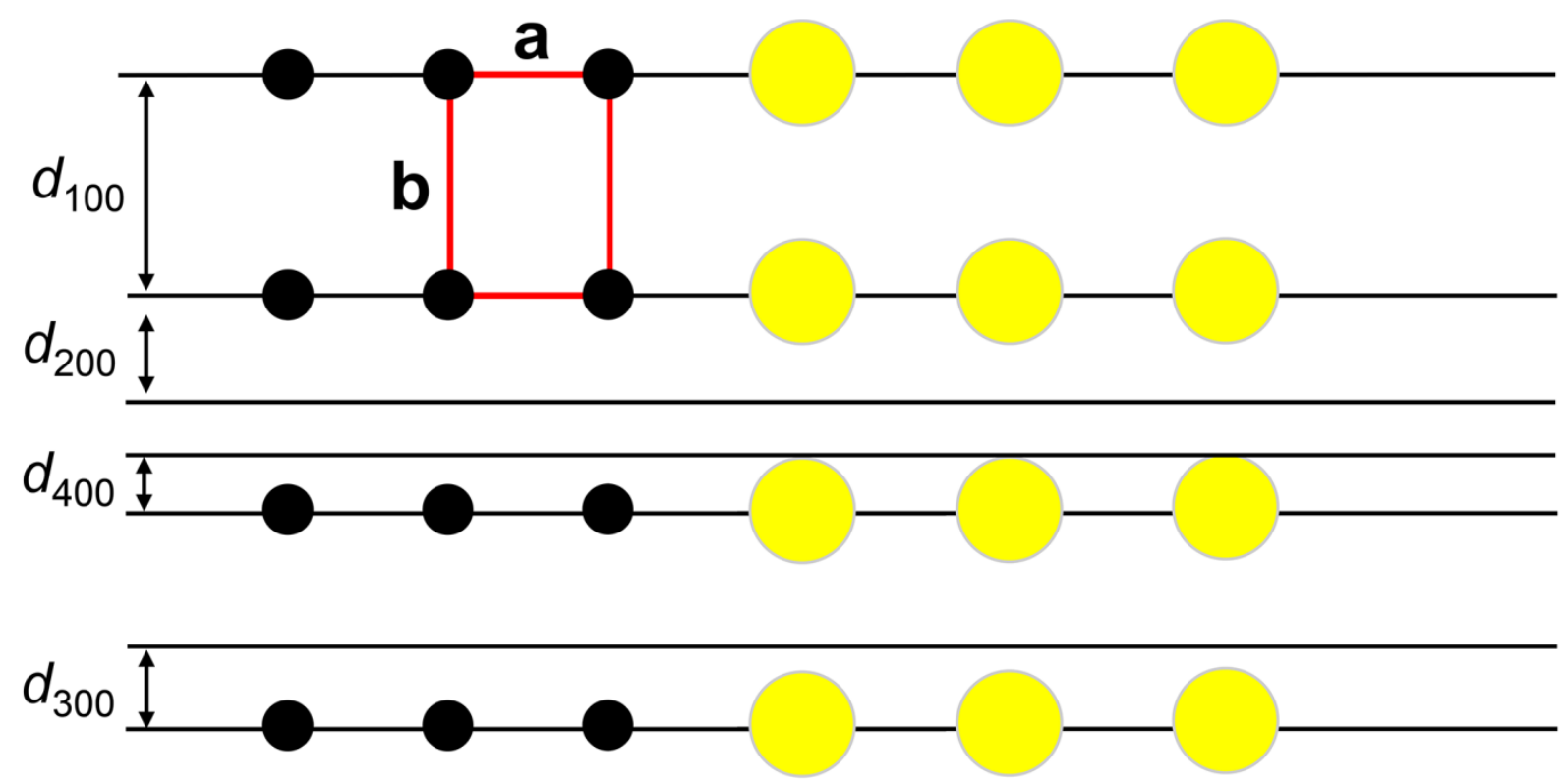

Figure S7. Schematic of the 1D smectic structure. $d$ is the distance between the facets created by the GNRs. The X-rays were diffracted at each $d$ of the GNRs. 
(a)

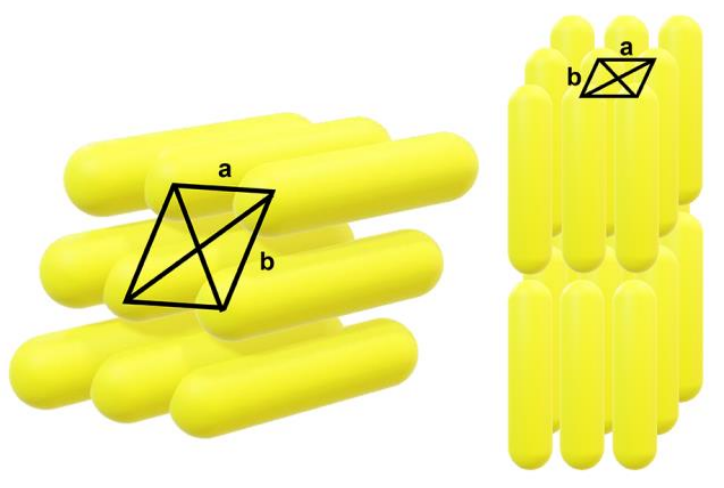

(b)

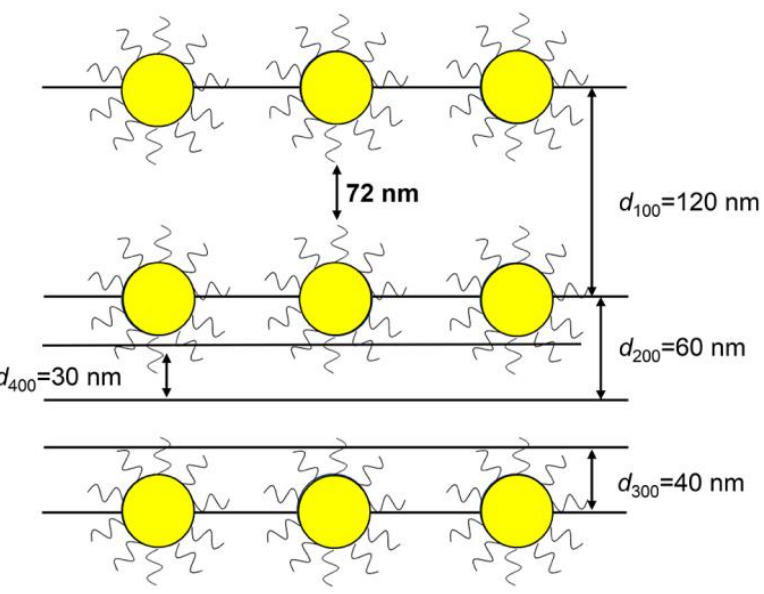

Figure S8. (a) Diagrams of smectic ordering of rectangular GNRs@PS $(a \neq b)$. (b) Schematic of the smectic ordered structure viewed along the electric field direction. The radius, polymer length, and rod-to-rod distance of the GNRs are 12, 12, and $72 \mathrm{~nm}$, respectively. The ordered structures are formed over a wide range. 


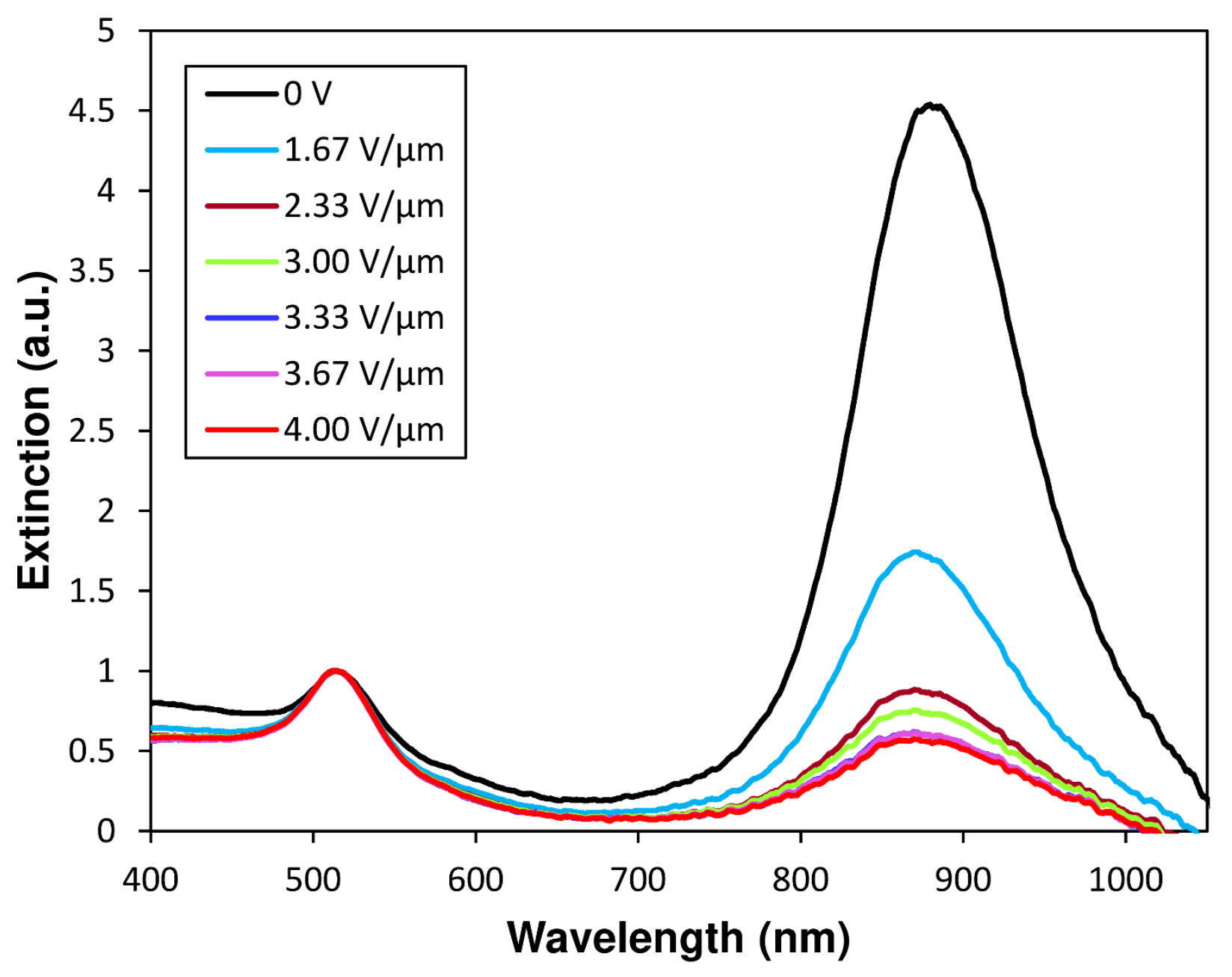

Figure S9. Absorption spectra of the GNRs@PS $(A R=4.0)$ in carbon tetrachloride under an applied electric field. The changes almost matched those observed in toluene. 


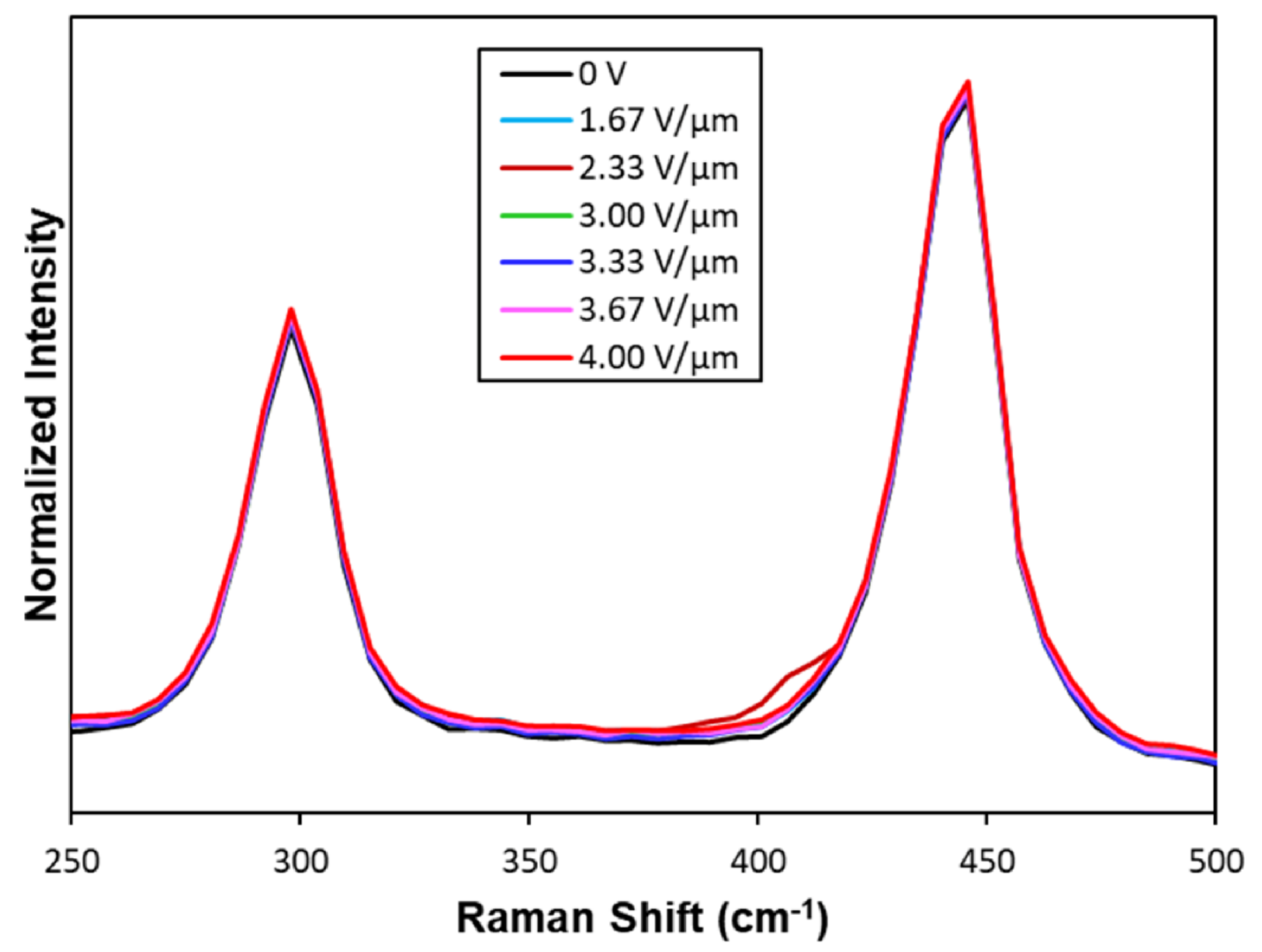

Figure S10. Raman spectra in carbon tetrachloride under the applied electric field. The electric field induced no obvious increase in the Raman peak of carbon tetrachloride. 
Table S1. Calculated $d$ at each facet of the 1D smectic structure, ratio to $d_{100}$, and the corresponding $q$ ratio (obtained by the conversion formula $q=2 \pi / d$ ).

\begin{tabular}{|c|c|c|c|c|}
\hline & $d_{100}$ & $d_{200}$ & $d_{300}$ & $d_{400}$ \\
\hline Calculation $d[\mathrm{~nm}]$ & $\mathrm{b}$ & $\mathrm{b} / 2$ & $\mathrm{~b} / 3$ & $\mathrm{~b} / 4$ \\
\hline$d$ [ratio] & 1 & $1 / 2$ & $1 / 3$ & $1 / 4$ \\
\hline$q$ [ratio] & 1 & 2 & 3 & 4 \\
\hline
\end{tabular}


References

(1) Ye, X.; Zheng, C.; Chen, J.; Gao, Y.; Murray, C. B. Using Binary Surfactant Mixtures To Simultaneously Improve the Dimensional Tunability and Monodispersity in the Seeded Growth of Gold Nanorods. Nano Lett. 2013, 13, 765-771.

(2) Nikoobakht, B.; El-Sayed, M. A. Preparation and Growth Mechanism of Gold Nanorods (NRs) Using Seed-Mediated Growth Method. Chem. Mater. 2003, 15, 1957-1962. 
(3) Sau, T. K.; Murphy, C. J. Seeded High Yield Synthesis of Short Au Nanorods in Aqueous Solution. Langmuir 2004, 20, 6414-6420.

(4) Bakshi, M. S.; Singh, J.; Singh, K.; Kaur, G. Mixed Micelles of Cationic Gemini With Tetraalkyl Ammonium and Phosphonium Surfactants: the Head Group and Hydrophobic Tail Contributions. Colloids Surf. A 2004, 234, 77-84.

(5) Bakshi, M. S.; Singh, J.; Singh, K.; Kaur, G. Mixed Micelles of Cationic 12-2-12 Gemini With Conventional Surfactants: the Head Group and Counter ion Effects. Colloids Surf. A 2004, $237,61-71$.

(6) Walsh, M. J.; Barrow, S. J.; Tong, W.; Funston, A. M.; Etheridge, J. Symmetry Breaking and Silver in Gold Nanorod Growth. ACS Nano 2015, 9, 715-724.

(7) Tong, W.; Walsh, M. J.; Mulvaney, P.; Etheridge, J.; Funston, A. M. Control of symmetry Breaking Size and Aspect Ratio in Gold Nanorods: Underlying Role of Silver Nitrate. J. Phys. Chem. C 2017, 121, 3549-3559.

(8) Cheng, J.; Ge, L.; Xiong, B.; He, Y. Investigation of pH Effect on Gold Nanorod Synthesis. J. Chin. Chem. Soc. 2011, 58, 822-827.

(9) Thambi, V.; Kar. A.; Ghosh, P.; Paital, D.; Gautam, A. R. S.; Khatua, S. Synthesis of Complex Nanoparticle Geometries via pH-Controlled Overgrowth of Gold Nanorods. ACS Omega 2019, 4, 13733-13739.

(10) Fontana, J. P. Self-Assembly and Characterization of Anisotropic Metamaterials. Thesis (Kent State University, 2011) 
(11) Fontana, J.; Costa, G. K.-B.; Pereira, J. M.; Naciri, J.; Ratna, B. R.; Palffy-Muhoray, P.; Carvalho, I. C.-S. Electric Field Induced Orientational Order of Gold Nanorods in Dilute Organic Suspensions. Appl. Phys. Lett. 2016, 108, 081904. 